\title{
Ideological cultures and media discourses on scientific knowledge: re-reading news on climate change
}

\begin{abstract}
Anabela Carvalho
Focusing on the representation of climate change in the British "quality press," this article argues that the discursive (re)construction of scientific claims in the media is strongly entangled with ideological standpoints. Understood here as a set of ideas and values that legitimate a program of action vis-à-vis a given social and political order, ideology works as a powerful selection device in deciding what is scientific news, i.e. what the relevant "facts" are, and who are the authorized "agents of definition" of science matters. The representation of scientific knowledge has important implications for evaluating political programs and assessing the responsibility of both governments and the public in addressing climate change.
\end{abstract}

\section{Introduction}

The media have a crucial responsibility as a source of information and opinions about science and technology for citizens. Public perception and attitudes with regard to those domains are significantly influenced by representations of scientific knowledge conveyed by the press and other mass means of communication (Wilson, 1995; Krosnick et al., 2000; Corbett and Durfee, 2004).

Like any other dimensions of reality, science is reconstructed and not merely mirrored in the media. Depictions of the world in the media result from a series of choices such as whether an issue will make the news, the highlight it will be given, and who is going to speak for it. Operations of codification of the issue into media discourse are directed by the perceived interest and social impact of a topic, as well as other "news values," economic considerations and editorial lines. Particular values and worldviews are produced, reproduced and transformed in media discourses; others are excluded from them (e.g. Bennett, 1988; Fairclough, 1995; Allan, 1999).

Significant challenges are presently posed to societies by complex scientific issues such as biotechnology, nanotechnology and climate change. This article focuses on the last. The claim that there is an anthropogenic influence in the climate system is nowadays widely consensual (IPCC, 2001). However, media depictions of the issue often suggest that the scientific community is divided in the middle. In association, many aspects of climate change politics are heavily contested. In the social circulation of the meanings associated with this issue, the media are a central arena and certainly play a part in shaping public and political options. This article will analyze discursive representations of scientific knowledge of climate change and unpack the ideological standpoints that are dominant in the British "quality press."1 


\section{Science, ideology and the media}

Studies of the relation of science and the media were for long dominated by a "transmissional" notion of communication. The "canonical view," typically conceptualizing science communication as "popularization," was centered on issues of quantity and rigor: how much scientific knowledge was reported in the media and how accurately (cf. Bucchi, 1998). ${ }^{2}$ Efficiency in the flow of data seemed to be the main goal.

In recent decades, research has become more sophisticated. Awareness of the media's transformative logics and mechanisms has led to investigation of the news values in operation in science reporting, the representations of risk associated to environmental issues, as well as the multiple modes of consumption of mediated meanings of science and the environment (e.g. Burgess et al., 1991; Anderson, 1997; Allan et al., 2000). As the constitutive role of language became clearer, attention turned to the discursive processes involved in the management of science and policy (e.g. Hajer, 1995).

Studies of media coverage of science have concluded that news values are applied to science and any other topics in similar ways (Friedman et al., 1986; Einsiedel and Coughlan, 1993; Hansen, 1994). Novelty, controversy, geographic proximity and relevance for the reader, for example, are important determinants in the selection of science news.

Various scholars have contributed to a better understanding of media representation of climate change. Boykoff and Boykoff (2004) have argued that the journalistic norm of balance has led to biased depictions of knowledge on climate change in the US prestige press with an excessive weight of those that deny its anthropogenic origins or that the problem is scientifically provable. Antilla (2005) has analyzed the frames constructed by a large number of American newspapers and wire services in relation to climate change science between March 2003 and February 2004. She contrasts the growing consensus in the scientific community with a media-generated image of controversy or uncertainty, with a great deal of attention being given to a handful of climate "skeptics."

In a wider analysis of the insertion of media coverage in social action, McCright and Dunlap (2000, 2003) have examined how the anti-environmental movement mobilized in the US to construct the "non-problematicity" of global warming by constructing alliances between conservative think tanks, fossil fuel interests and "skeptic" scientists, and looked at the repercussions of this in the media and in policy-making. Other research on media coverage of the greenhouse effect in the US has emphasized the cyclical nature of narratives (McComas and Shanahan, 1999) and the variable weight of different social actors (Trumbo, 1996) in the media.

The media are key elements in the mediation of the "relations of definition" (Beck, 1992) between science, the public and the political spheres. The notion of science as an "ivory tower," exempt from public exposure and debate, is increasingly inadequate. As our "risk society" (Beck, 1992) generates new problems that require scientific interpretation but affect us all, science is asked to "come out to the street" and to be the basis of political decisions. Policy-makers often expect scientists to provide answers to problems that are debated in the media and other public arenas, and make a variety of public uses of science to legitimize action or inaction. Scientific knowledge is also utilized by a number of other social actors, including business and activists, to justify particular programs. As new links are established between citizens, scientists, politicians and media professionals, the embeddedness of science and politics has become increasingly public and science has become more exposed to criticism, contestation and deconstruction.

As a forum for the discourses of others and a speaker in their own right, the media have a key part in the production and transformation of meanings. Gamson (1999) suggests that the 
media can be an important "validator" of science. Considering facts as "institutionally validated claims about the world" (p. 23), Gamson argues that social institutions with the capability to bestow facticity on claims in a given realm are the "primary validators." An example is the Intergovernmental Panel on Climate Change (IPCC) in the field of climate change. The media act as "secondary validators" by reporting on and diffusing the factual claims of "primary validators." But the media also act as "primary validators" in certain cases. In controversial issues, their gatekeeping role is more important as they decide which "wouldbe primary validators will be given voice, and how much of a voice" (p. 24).

In the media, as in other arenas, there is no such thing as "pure facts." Instead, "truth claims" are embedded with certain worldviews, judgments and preferences. A number of analyses of the representation of social and political matters in the media have indicated that there are significant ideological factors in play (Hall et al., 1978; van Dijk, 1991; Fairclough, 1995). Various authors have noted that there is no systematic critique of science (Nelkin, 1987; Gregory and Miller, 1998) in the media, which tend to reinforce the dominant "ideology of science"- the social authority and power of science as the guardian of the truth (Edmond and Mercer, 1999). News organs would thus contribute to a reification of science.

Wilkins (1993) is perhaps the most relevant scholarly antecedent to this study. Looking at the American press coverage of the greenhouse effect she emphasized the role of values in media representations. In the line of the seminal study on newsmaking by Gans (1979), she pointed out "progress," "innocence" and "institutionalization of knowledge" as the dominant values that direct the selection and framing procedures of the greenhouse effect in the media.

Nevertheless, the role of ideology in media representations of science is still blatantly under-researched. To what extent do media readings of scientific knowledge and evaluations about the worthiness, accuracy and interest of scientific "facts" depend on normative and axiological issues? How does science reporting relate to political standings in the media? This article aims at filling this gap and questioning the role of values and idea(l)s in the press's discursive reconstitution of science.

After the proclaimed "end of history" and "death of ideology," there is now a revived interest in ideological issues. Still, the field remains contentious, with the very concept of ideology being subjected to multiple definitions (Eagleton, 1991). In the Marxist tradition, ideology has often been linked to social domination and to distortion of reality. Alternatively, I understand ideology as a system of values, norms and political preferences, linked to a program of action vis-à-vis a given social and political order. People relate to each other and to the world on the basis of value judgments, ideas about how things should be, and preferred forms of governance of the world. In other words, ideologies are axiological, normative and political. Besides government and society, the referents of ideologies may include, for example, the economy and the relations between humans and the environment. Ideologies always involve a vision of an ideal world with which lived existence is confronted. They therefore legitimate "action for the preservation, reform, destruction and reconstruction of a given order" (Seliger, 1977: 119-20).

Lull (1995) claims that the strength of ideology depends on its communication. I view media discourse and ideology as mutually constitutive. On the one hand, media texts result from ideological standpoints. On the other hand, media texts produce ideology: news and other media genres always reproduce and/or challenge a certain ideology. The media should not be seen as mere conveyers of the ideologies of other actors. Besides allowing or disallowing other social actors to advance their ideological standings, the media can also have an important agency in bringing in new ideological readings of issues or confronting those of the dominant. 
What ideological issues are interplayed in the discursive construction of science on climate change in the British "quality press" and how do such issues shape depictions of knowledge claims? These are the questions that will drive the discussion below.

This article focuses mainly on media texts where the main topic is knowledge claims regarding climate change (e.g. scientific progress documented in articles, conferences and reports). Given the crucial science-policy nexus, the discussion will also involve several key political events and their interrelation to scientific knowledge. See Carvalho (2005) for an analysis centered on the politics of climate change in the press, i.e. representations of issues, events and debates related to the political management of climate change, at the national and international levels (e.g. summits, political speeches and policy programs).

\section{Climate change sciences in the British press}

The article will focus on the representations of climate change in three British "quality" newspapers-The Guardian (and the Sunday broadsheet The Observer), The Independent (including the Independent on Sunday) and The Times (including The Sunday Times). The choice of these newspapers results from the interest in examining, as fully as possible, the arguments and perspectives of various social actors on climate change. Such a debate on this complex issue is excessively simplified or excluded in other media. The chosen titles correspond to a relatively small part of overall newspaper circulation in the United Kingdom, which is dominated by the so-called popular and mid-market newspapers (e.g. The Sun, Daily Mail, News of the World). However, the selected newspapers have an important power of agenda-setting for the public and the other media. Finally, they are preferred by politicians and other decision-makers and therefore their discourse matters even more (see Sparks, 1987).

These newspapers span the political spectrum. The Times is a Conservative paper, committed to the "establishment" and to the sovereignty of traditional institutions. In this group of newspapers, The Guardian is the only one that is not owned by a conglomerate and is the most leftist. The youngest of the three, The Independent leans towards the Labour Party but often oscillates somewhat to the right. ${ }^{3}$

The period covered by the analysis is 1985 , when the issue started rising to political attention, although incipiently, to 2001, when the IPCC's Third Assessment Report was released. Excluding passing references to the issue, 4,487 "core" articles on climate change appeared in the three newspapers in this time interval. As shown in Figure 1, levels of coverage fluctuated significantly with a first rising trend up to 1990, a decline from 1991 until 1996 (with small ebbs and flows) and another increase from 1997 that hit the highest point in 2001.

The articles were collected from CD-ROMs, and the FT-Profile and Lexis-Nexis databases. Search keywords were "climate change" or "global warming" or "greenhouse effect." All journalistic genres, from features to editorials, were considered, except readers' letters.

A detailed discourse analysis was done of all the articles published from 1985 to the end of 1988, when attention to the issue started escalating. From there onwards, the focus was on those "critical discourse moments" that could bring challenges to discursive constructions of the issue. Such moments are indicated in the discussion below.

The innovative analytical framework employed in this research draws mainly on Critical Discourse Analysis (van Dijk, 1988; Fairclough, 1995; Wodak et al., 1999). It operates at the textual and contextual levels. In the text, attention is given to morphological characteristics and structural organization of texts (page number, size, headlines, etc.) $;{ }^{4}$ objects (themes) of 


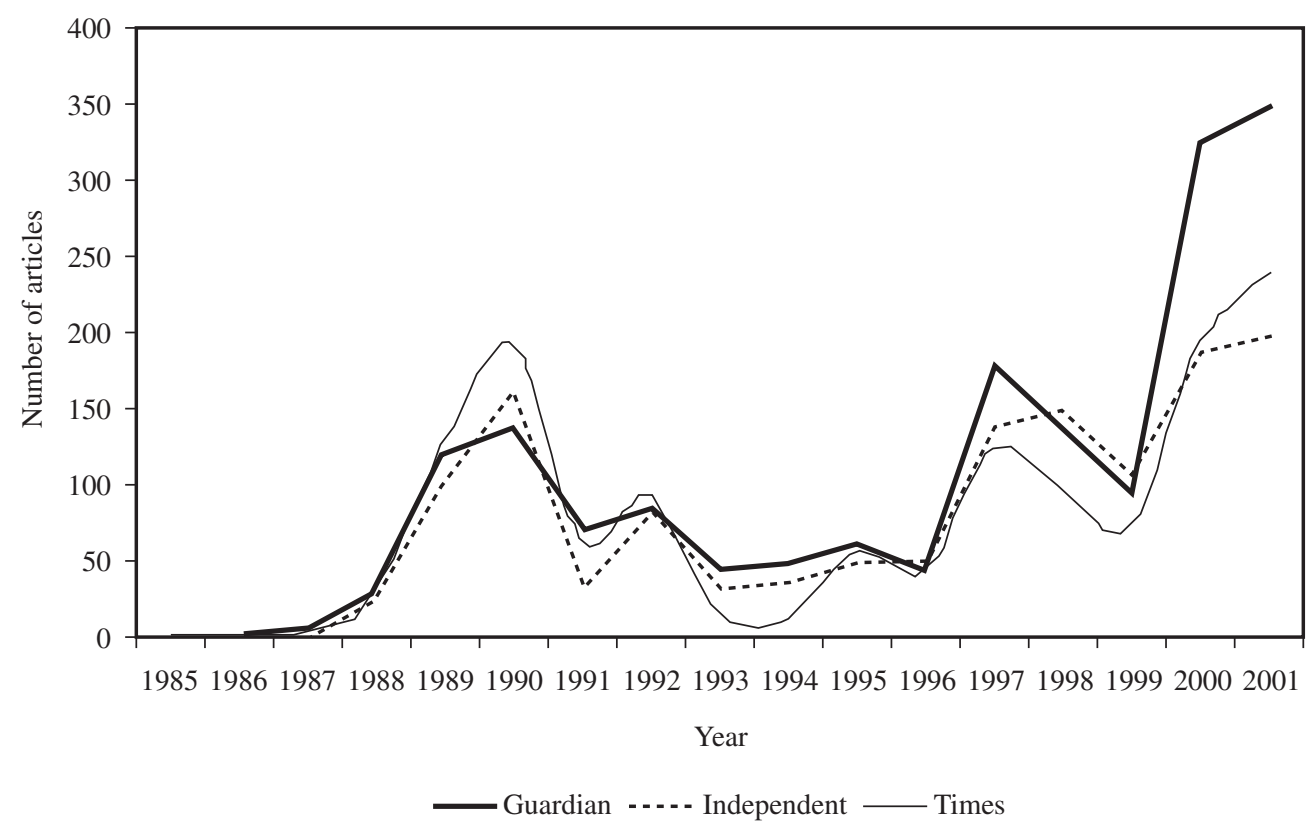

Figure 1. Number of newspaper articles on climate change in The Guardian, The Independent and The Times: 1985-2001.

discourse; actors; language and rhetoric; discursive strategies (forms of discursive manipulation of "reality" by social actors in order to achieve a certain goal); and ideological standpoints. Contextually, the analysis below will focus on a comparative-synchronic axis (simultaneous depictions of the climate change in different newspapers) and a historicaldiachronic axis (temporal sequences and evolutions). The primary unit of analysis is the individual text. From the text, we will attempt to identify recurrent traits of discourse in each newspaper both in a given historical moment and over time. The extensive results of this analysis are summarized in the following sections. Comparison between newspapers and historical evolution will be emphasized in the discussion.

Given the weight of the analysis of "frames" and "framing" in academic tradition, especially in North America, a brief comparison with Critical Discourse Analysis is required. In media studies, most research has treated frames as a form of categorization, organizing discourse around central ideas or principles (e.g. Gamson and Modigliani, 1989) or as perspective (or selection and salience), calling attention to certain aspects of reality and obscuring others (e.g. Entman, 1993). Critical Discourse Analysis allows for a richer examination of the resources used in any type of text for producing meaning. It shares with framing analysis an interest in the variable social construction of the world but puts a stronger emphasis on language and on the relation between discourse and particular social, political and cultural contexts.

\section{The social construction of scientific authority}

The earlier years of reporting on climate change tell a known story about media discourse on science: a novel knowledge claim is reconstituted in the press in a way that reinforces the social power of science. As exemplified by the excerpts below, an image of certainty was 
clearly built by The Times (emphasis has been added to parts that present the relation between temperature rises and the enhanced greenhouse effect as uncontested).

An American meteorologist, Kerry Emanuel, of Massachusetts Institute of Technology, believes that the rise in temperature due to the greenhouse effect in tropical latitudes will make hurricanes and cyclones much more destructive even than they are today. ... So Dr Emanuel calculates that the maximum destructive force of cyclones in the Bay of Bengal and the Gulf of Mexico will be increased by as much as 60 per cent. Other meteorologists believe it is possible to quarrel with Dr Emanuel's detailed conclusions. But the existence of the greenhouse effect is generally accepted. It is thought already to have caused an average temperature rise of around $0.5 \mathrm{C}$ and to be due to raise average temperatures by a further $2 C$ by $A D 2050$ with greater rises in some areas. The effects of this on cyclones could be less severe than those predicted by Emanuel, but they might be even worse. It is also possible, say other meteorologists, that a further effect of the warmup will be to increase the frequency as well as the severity of tropical cyclones and hurricanes. (John Newell, "How Greenhouse Effect Might Help Cyclones to Grow," The Times, 20 April 1987)

Already in 1986, Pearce Wright reported that

... the latest results of studies by the National Centre for Atmospheric Research at Boulder, Colorado ... show that if the level of human activity producing the change continues at the present level, the increase will add at least one degree Centigrade and perhaps as much as five degrees Centigrade before the year 2050. ("Gases Pushing up Ground-level Temperatures," The Times, 21 January 1986)

Linguistic choices such as the word "will" for talking about impacts forecasted by scientists, the use of terms such as "detailed and reliable records" (see following article), and the recurrent employment of the word "show" in relation to records or results contributed to depicting climate sciences as a consensual and reliable domain.

[The Climatic Research Unit of the University of East Anglia] was established some 12 years ago by Professor Hubert Lamb to create detailed and reliable records of the climate of the past, with the object of then developing practical advice for the future. The scientists have already shown that the agricultural growing season in Europe has shortened, and even better understanding about the longterm trends in the climate is expected to be of value for planning large-scale, energy projects. ... Now, more detailed records assembled by Dr Tom Wigley, director of the research unit, show that the rise in carbon dioxide that started with the industrial revolution is greater than previous estimates.... One implication of this is that the warming of the atmosphere by the "greenhouse effect" during the last hundred years has been greater than that allowed for in previous calculations. (Pearce Wright, "Gloom Over Weather Patterns," The Times, 13 August 1985)

Scientists were the uncontested central actors and exclusive definers of climate change up to the end of 1988. Newspapers deployed a discursive strategy of authorization (van Leeuwen and Wodak, 1999): authors of press articles sought to legitimate knowledge claims by resorting to the authority of individuals and institutions holding positions of recognized importance. The scientific journals Science and Nature were the sources of six out of 21 articles published between 1985 and 1987 in The Guardian and The Times. The names of researchers and their institutional affiliation were referred in 20 articles. At a higher level, we can speak of a strategy of rationalization: climate change was represented as a tractable and potentially solvable scientific problem, to be dealt with by credible agents. 
Respect for science and scientists is a socially widespread value that is clearly in evidence in the press in this period (see Irwin, 1995). The representation of climate change described above strengthens the authority of science. One important consequence is that this provides the justification for further research: "More investment in the relatively cheap forms of research required to predict such effects is required to be more certain of what they will be" (John Newell, 20 April 1987).

In his analysis of the American press, Trumbo (1996) has also found that in the late 1980s scientists were the dominant social actors in news articles. Boykoff and Boykoff (2004: 130) have claimed that, unlike later periods, in 1988 and 1989 journalists emphasized consensus in relation to climate change and its anthropogenic origins. McComas and Shanahan's (1999) study provides further evidence of a trend from certainty to controversy.

However, mediations of climate change up to this moment did not raise any challenges for ingrained habits and dominant institutions. In fact, in this period, the British press clearly underestimated the risks associated to climate change, and refrained from presenting its possible consequences. In a similar vein, newspapers remained silent about responsibility for the problem, not only leaving unquestioned the economic and social practices that generate greenhouse gases but also omitting references to the role of political institutions.

Media coverage of the greenhouse effect changed at the end of 1988 with the integration of political issues into the analysis. This was stimulated by Margaret Thatcher's appropriation of the risks of climate change to promote nuclear energy and dismantle the coal industry (Carvalho, 2002, 2005). Climate change thus became quite prominent in the political and media agendas, pushed by the Conservative government but also by environmental organizations and political forces in opposition who demanded solutions that contrasted with the government's.

Whereas The Times ${ }^{5}$ replicated Thatcher's discourse on nuclear energy, The Guardian ${ }^{6}$ was the stage for a wave of contestation of the government's proposals for addressing the problem of greenhouse gas emissions. As in later years, The Independent did not have such a clear-cut position, although several articles ${ }^{7}$ advanced alternative policies, such as investment in renewable energies and public transport. At the end of 1988, the scope of potentially necessary political, social and economic transformations to address climate change started to become visible.

\section{Scientific uncertainty becomes politicized}

The publication of the First Assessment Report of the Intergovernmental Panel on Climate Change (IPCC) in May 1990 (IPCC, 1990) ${ }^{8}$ should have been a key moment in the discursive construction of the greenhouse effect. Adjoining some of the top climate scientists around the world, the IPCC report represented the consensual knowledge that could form the basis for policy decisions. Nevertheless, at this time, climate studies were still characterized by a large degree of uncertainty. Uncertainty is a difficult issue for reporters, as news values of clearness and unambiguity demand "facts" and lead to a streamlined image of scientific knowledge (cf. Nelkin, 1987, 1991).

In the field of climate change, uncertainty permits varying prognostics, which are fundamental for decision-making. Definitive evidence of the full impact of human-generated greenhouse emissions may come too late to avoid the worst effects. Crucial judgments thus have to be made in which the short- and the long-terms may be in tension. The illations the media draw from uncertainty are profoundly ideological. In climate change there is a great risk for future generations, for nature, and for geographically distant peoples, amongst other examples. It is 
the worth attributed to those realities and the values that may be at stake, such as freedom, equity and responsibility that may justify action or inaction.

Both in "Climate Crisis Report Throws down Gauntlet" (Paul Brown) and in a long feature entitled "Environment: Heat and Dust-ups" (Nigel Williams), printed on 25 May 1990, The Guardian acknowledged the existence of uncertainty. Yet, calls for high cuts in emissions are to be found in these texts. Support for a precautionary approach to climate change was to remain constant in The Guardian throughout time. Therefore, as Margaret Thatcher proposed stabilization of emissions by 2005 as the British target, The Guardian led a campaign of contestation where the scientists' claims of a necessary 60 percent reduction in emissions were often evoked. ${ }^{9}$

In The Times, the launch of the IPCC report was dominated by Thatcher's attempt to appropriate climate change. The IPCC claims were mainly read in conformity with Thatcher's propositions. However, as attention to climate change was heightened, The Sunday Times revealed a very reactionary attitude in three long articles from 27 May 1990: "Green Hysteria Sets Red Alarm Bells Ringing" by David Sapsted; "Global Fawning: Global Warming" by Bryan Appleyard; and "Greenhousemongers" (Leading Article, unattributed). Environmentalism is labeled as "religious dogma," "sentimental ululation" and "green Stalinism."

The words below, which appear in Sapsted's article, are typical of a Promethean perspective of man's relations with nature (Dryzek, 1997):

... a belief in the curiosity and audacity which have always driven mankind on towards new horizons. The latest new horizon, thanks to the Hubble space telescope, is hundreds of light years away. ... perhaps, instead of bending down to look at the oil slick or the cracked concrete at our feet, we should be stretching upwards and looking outwards to the stars.

Like the Greek Titan Prometheus who stole the fire from Zeus and gave it to humans, man in this view has infinite possibilities in his relation to the environment. Economic growth and progress are unlimited. ${ }^{10}$

The greenhouse effect was classified as the "latest scientific faddism" and the "greenhousemongers" discredited ("Greenhousemongers," 27 May 1990). The Sunday Times attempted to contradict mainstream scientific claims and argued that "scientists are deeply divided about how much global warming will result from an increase in greenhouse gases" ("Greenhousemongers," 27 May 1990). This discursive construction suggested that the scientific community was split in the middle about this issue when, in fact, disagreement with the IPCC was very minoritarian.

In "Greenhousemongers 2" (long Leading Article, unattributed, 3 June 1990) The Sunday Times expressed fears that "in a fit of excessive and emotional environmentalism, governments could squander billions that might be better spent elsewhere." Under the argument of a "hard-headed examination" (27 May 1990) and a sensible, rational and pragmatic position, there was resistance to government intervention in relation to climate change. Values like individualism and market liberalism came through in the text.

In a free society the correct course is not to ban people from using cars ... There is a clear need to develop a set of mechanisms to make markets work better to reduce pollution. (“Greenhousemongers 2," 3 June 1990)

In contrast, empathy with geographically distant peoples or a sense of global responsibility was absent from The Sunday Times: 
Bangladesh may be in great danger from flooding in the next century; but the greenhouse effect could also bring huge benefits to farming in Canada and the Soviet Union, allowing them to support far greater populations. Mass migration is a common event in world history, and it might make more sense to live with some of the consequences of the greenhouse effect than to devote effort and resources to trying to thwart them. ("Greenhousemongers 2," 3 June 1990)

This set of articles is particularly interesting because, unlike the ones previously cited, they are opinion articles and two of them are labeled as "leading articles," a status that indicates a stronger institutional endorsement by the newspaper of the ideological standpoints displayed therein.

This discursive shift in The Times in relation to earlier years does not mean that there was a transformation in the ideological stances that are dominant in this newspaper. It just suggests that in the hierarchy of values subscribed by The Times, scientific authority ranks below Conservatism, the preference for a non-regulatory government and reinforcement of the social and economic status quo. In this ideological constellation techno-science is subjected to other ideological referents, such as politics and economics. Ironically, it was when the political powers turned to climate change that The Times started adopting a suspicious attitude towards science. This tensely coexisted with a sensationalist dramatization of climate change. Typically, the newspaper displayed a double allegiance-to the Conservative government in power and to the stability of economic and social structures. But when an issue heightened by the government started posing challenges to the status quo, The Times championed the latter.

In The Independent, several representations of the IPCC report created a sense of danger. Two prominent news pieces appeared, on 26 May 1990- "Scientists Identify Growing Danger of Global Warming" (unattributed, page 3) and on 27 May 1990- “The Greenhouse Time Bomb: Authors of UN Report Say New Data Shows they have Underestimated Dangers of Global Warming" (by Steve Connor, page 1).

Quite critical of Thatcher's proposals, Nicholas Schoon used "expert" knowledge to claim for stronger governmental action on greenhouse gases ("Experts Say the World Must be Led by Example," 26 May 1990, page 3). Moreover, The Independent advocated precautionary action in an editorial headlined "Progress and the Environment" (26 May 1990) where the newspaper tried to harmonize environmental protection with "progress": "A concern for the environment tends to improve the quality of life and of investment, rather than acting as a drag on progress."

A general discursive transformation is worth noting here. By 1990, science had lost most of the initial high ground in definitions of the greenhouse effect in the press (cf. Trumbo, 1996). Governmental moves to control and recontextualize understandings of the greenhouse effect led to most media discourse being taken over by politicians and other actors.

\section{Ideological tests of scientific credibility}

The IPCC's Second Assessment Report was released in December 1995. For the first time, it stated clearly that human activities have an impact on climate: "the balance of evidence suggests a discernible human influence on global climate" (IPCC, 1996: 4). It also promoted substantial mitigation measures. Prior to the IPCC report, it is worth looking at media reconstructions of science around the time of the First Conference of the Parties to the United Nations Framework Convention on Climate Change (UNFCCC) ${ }^{11}$ that took place in Berlin in March 1995. The stabilization of emissions at 1990 levels agreed in Rio had been shown to be insufficient and the summit had a mandate to define quantified reduction objectives. 
Analysis of science reports in the press in 1995 indicates that strong ideological filters were in place in the three newspapers. At a time when scientific knowledge on climate change was becoming more solid and consensual, an image of uncertainty and disagreement was amplified by The Times and by some in The Independent.

The selection newspapers make of scientists as "authorized definers" of climate change is very suggestive. In 1995, The Times opted to give space to some of the most outspoken American "skeptics." Occasional references to the American "skeptics" had already appeared in earlier years in this newspaper, especially its Sunday version, ${ }^{12}$ but were not as frequent. This rise in visibility in 1995 is consistent with the findings of McCright and Dunlap (2003) about the American press, although there the weight of "climate contrarians" was very significant since 1990 (see also Boykoff and Boykoff, 2004).

These scientists are known to have economic ties to fossil fuel companies and/or institutional commitments to Republican bodies and conservative think tanks (see Gelbspan, 1997; McCright and Dunlap, 2000, 2003). They tend to be very vocal and highly organized (Lahsen, 2005). In a lengthy article appearing on the prominent page 3 (continued on page 6), entitled "Global Warming: Why Scientists are Feeling the Heat" (26 March 1995), The Sunday Times' Sean Ryan finishes his somewhat ambiguous reasoning on the science of climate change and the need for action with the following words:

Lindzen fears the Berlin summit could set governments on a course that would be wrong but legally unalterable before the year 2010. "If science in a few years can no longer sustain these forecasts, nothing will stop the policy. They are deciding what the policy will be regardless of the science."

This discursive construction of the problem enhances uncertainty and presents politics as dangerous, at least the kind of politics that was being decided in Berlin. What appears to be at stake here is the role of regulatory policies by governments or intergovernmental bodies towards which The Times is generally mistrustful.

The same article illustrates the striking differences between newspapers in interpreting the standings of scientists, in the case of the chair of the IPCC's Working Group I.

Sir John Houghton ... frankly acknowledges the uncertainties. The IPCC predicts warming of at least $0.2 \mathrm{C}$ a decade endorsed by 400 scientists but he admits: "We're not saying we've seen it because the signal is still hidden somewhat in the noise. We are feeling more confident that we might be there." (emphasis added)

In what context were Houghton's words uttered? Was there an interpellation of the journalist that motivated this answer? And should we see in Houghton's words a basis for postponing action or simply an indication that the climate sciences, like all others, operate within certain limits of certainty? The words of Houghton in The Guardian (Paul Brown, "Global Warming Summit at Risk," 25 March 1995) clarify where he stood. "There is no doubt that global warming is happening. It is inevitable. The question is whether we can slow it down enough to avert the worst effects." Other articles in The Guardian sustained this reconstruction of Houghton's views. ${ }^{13}$

Throughout the year of 1995, The Times carried several texts that denied or cast doubts on the greenhouse effect, or on its causal relation to human practices. Those news reports were authored by William Burroughs ${ }^{14}$ and by Nigel Hawkes. ${ }^{15}$ Hawkes was the science editor of The Times and therefore had a big responsibility in defining interpretative lines for climate change. When he did not dismiss the greenhouse effect, he advanced some Promethean, technical-fix-type solutions to solve it, such as dumping enormous amounts of iron in the 
oceans ${ }^{16}$ and undertaking a massive plantation of trees. ${ }^{17}$ Yet, there were a number of articles in The Times that referred to indicators of climate change. They were all authored by environment correspondent Nick Nuttall. ${ }^{18}$ Moreover, Nuttall often made the connection between climate change and human activity. ${ }^{19}$

Some would argue that this indicates that The Times made a "balanced" coverage of the issue, a claim that the newspaper itself would certainly make. However, as pointed out by Boykoff and Boykoff (2004), "balance" can equal "bias" if we are talking about an issue that is largely consensual within the scientific community. In any case, these differences within The Times suggest that the ideology that is dominant in a newspaper does not imply a completely standardized discourse. We will come back to this issue in the conclusion of this article.

The scarcity of articles addressing the IPCC's Second Assessment Report is the first indicator of the relative devaluation that The Times made of the event. Even more telling is the fact that two of the three articles on the topic rejected the validity of the IPCC's claims. In "The Heat of Argument" (30 October 1995), Nigel Hawkes stated: "An apocalyptic vision was conjured up last week in a new report issued by the ... IPCC ... Vast areas will flood, people may starve, glaciers will melt and deserts expand as a result of global warming ..." The headline, the word "conjured" and the irony in this opening paragraph produced a highly derogatory image of the IPCC. As climate change rose in the international political agenda, and the need for significant transformations in policies and the economy became more widely accepted, The Times vividly refuted the authority of science and promoted an attitude of suspicion and mistrust with regard to scientists. Patrick Michaels, of the University of Virginia, was another "skeptic" enthroned by The Times in Hawkes' text. ${ }^{20}$ Michaels had been invited to give a conference by the Institute of Economic Affairs, known for its right-wing views and for the promotion of economic liberalism, an ideology in sympathy within The Times. In a later article_-"Mankind Blamed for Global Warming," 27 November 1995-Nigel Hawkes brought up contestation of the IPCC again.

Contrasting with The Times, The Independent advanced an image of scientific consensus with regard to climate change. This is immediately evident in the headline of a long feature from 15 October 1995: "Global Warming is Leading to Climatic Upheaval, Say Scientists: Experts Have Reached Consensus after Years of Disagreement" by Geoffrey Lean. In a similar vein, Nicholas Schoon authored an article entitled "Global Warming is Here, Experts Agree. Climate of Fear: Old Caution Dropped as UN Panel of Scientists Concur on Danger Posed by Greenhouse Gases" (page 3, 30 November 1995). Rhetorical strategies to reinforce scientific claims included discussing the pressures under which science is made, as Schoon spoke of "intense opposition" and of attempts to "water down" the report. The IPCC's reliability was also enhanced in "The Right Climate for Tax on Fuel" (long "comment" also by Nicholas Schoon, 16 October 1995). Here, Schoon advanced support for potentially unpopular fuel taxes. However, he guarded against social injustice by advocating protection of the poor and elderly as well as jobs. The value of social solidarity was advanced as corrective of policy options derived from the knowledge claim that climate change is occurring and should be avoided.

Lean presented greenhouse emissions as a severe menace in the article mentioned above (15 October 1995). The forecasted scenario was "as alarming as it could be for humanity" and "global warming could accelerate out of control," he warned. Nature can also be an ideological referent and here it is seen as fragile (cf. "myths of nature"-Schwarz and Thompson, 1990). A long-term perspective of the greenhouse effect was advanced in the front-page headline "Global Warming 'Will Last Centuries"” (Geoffrey Lean, Independent on Sunday, 15 
October 1995, title on page 1). Such a reading is consistent with an ideology of sustainable development - a version in which future environmental security is highly valued.

Paradoxically, The Independent also made room for the views of the "skeptics." In "Science 'Using Language of the Adman"” (Tom Wilkie, 1 December 1995), Richard Lindzen discredited the IPCC by arguing that it produced "waffle statements which don't say anything, which nobody can disagree with." The text attempted to dismiss claims of human interference in climate change, maintaining that the registered warming fell within the limits of natural variability.

In summary, The Independent amplified quite different messages about the science of climate change, depending on who wrote the articles. Lean and Schoon, whose articles were in numerical majority over other authors, promoted the IPCC's reliability, emphasized the seriousness of the risk and called for action; discrepant voices cast doubts on the IPCC report, and some attempted to deny or lessen the problem.

While in many of the previously discussed articles, ideological standings of newspapers were especially noticeable in issues related to the policy consequences of science, in other articles ideological standpoints were played at the very core of science. As it has global impacts, the analysis of climate change involves assumptions regarding societies with very different levels of "development" and calculations about the value of realities that may be affected or lost, including the value of human life. In The Guardian, a very long article by Richard Douthwaite, "Who Says that Life is Cheap?" (1 November 1995), focused on the valuation of human life in IPCC models, which are central to the scientific and policy-oriented reports this body produces. The IPCC had calculated the cost of lives by "estimating how much people would be willing to pay to avoid a higher death rate or having their land flooded."

As people in poor countries can't offer to pay very much, their deaths and the damages they will suffer were valued at much less than in wealthier countries, skewing the international distribution of the cost.

The value of equity is clearly at stake here. The Guardian advances a discursive construction that favors equality of treatment of all peoples. A similar debate and a sense of social responsibility had been advanced in the Independent on Sunday by Geoffrey Lean under the headline "One Western Life is Worth 15 in the Third World, Says UN Report" (23 July 1995).

In several articles, The Guardian constructed an image of crisis and a sense of urgency around climate change. The newspaper appeared clearly committed to mobilizing public concern by exposing the gravity of the problem. It spoke of a "very great ... danger," a "calamity" and a "threat to the future of life on the planet" in the articles mentioned below. The forecasts of the IPCC report were reported as certain: "The effects are real and we are feeling them. There is a great crisis ahead ... Millions will die in storms, floods and droughts. Many more will lose their homes and their livelihoods" (Paul Brown, "World's Burning Issue," 28 October 1995). In this dramatization of the future, the long-term and the well-being of others are taken into account. The value of responsibility is intertwined with this reading of science and was reinforced by this discursive construction.

A sense of empathy with different peoples around the world was promoted in discussions of the effects of climate change from Switzerland to Southern Africa: "people may face starvation and ruin ... the prospect of a refugee crisis is frightening." ${ }^{21}$

For a group of island nations ... [climate change] raises the prospect of disappearing beneath the waves during the next century. About 35 countries ... will either be washed 
over completely or lose a large part of their land surface if the worst predictions come true. They are not alone in this problem. Parts of Europe, including much of Holland and eastern England, are threatened too. (Paul Brown, "Climate: A Race against Time," 5 December 1995)

A notion of global connectedness was clearly present in Brown's reconstitution of the IPCC report. By fostering the experience of globality, The Guardian may be promoting a "global citizenship" (Szerszynski and Toogood, 2000). The public may feel more engaged with climate change and commitment to action may result from this ideological standpoint in media discourse.

Paul Brown also drew implications for policy-makers and the public: road traffic had to be reduced. Pointing to "carbon taxes" and to "cutting down on car journeys" 22 could be unpopular with an editor as this could antagonize with readers' wishes of individual freedom. But Brown stuck to the principles of socially shared responsibility and defense of an interventionist state. "We must find different ways of generating electricity and so use less oil and coal. We must drive fewer petrol and diesel cars" ${ }^{23}$ is the common imperative presented elsewhere. The juxtaposition of scientific visions of the future with the social and political practices that are to blame is conducive to self-reflection and re-examination of governmental action. Yet, it is crucial to note that, besides these episodic references, The Guardian did not really engage in spreading the message that consumption and mobility would have to be reduced if climate change were to be effectively tackled. Recently, Edwards and Cromwell (2005) have noted that The Guardian and The Independent did not do enough to point out to their audiences how climate change is related to "corporate obstructionism" and to "mass consumerism" which they continued to promote through advertising, their main source of revenue.

\section{Exposing ideological commitments}

Towards the end of the decade, new traits started emerging in the media discourse on climate change. Building on accumulated experience of reporting on the issue and having grown familiar with the institutions and actors in the field, journalists became more prone to discuss what goes on behind the scenes of the science and politics of climate change. Rather than "just sticking to the science facts," media professionals started exposing the interests, goals and ideological commitments of claims-makers.

The Third Conference of the Parties to the UNFCCC, held in Kyoto, Japan, on 1-10 December 1997, was an important "critical discourse moment." The Protocol agreed there mandated legally binding targets for reduction of greenhouse gases for the first time. This was a contentious goal, both prior to the summit and afterwards. It is therefore relevant to examine how newspapers reconstructed the scientific knowledge upon which the Kyoto Protocol was founded. More recently, another important date in the history of climate change science was the publication of the IPCC's Third Assessment Report in 2001. This document strengthened the certainty of human interference in the climate system and revised upwards the forecasts of temperature increase.

From the mid-1990s newspapers displayed an increased tendency to penetrate the backstages of science, to discuss the processes of science-making, their contingencies and limitations, actors' interests and commitments. ${ }^{24}$ In The Guardian and The Independent, this was not a strategy for dismissing scientific claims. Inversely, it was often a form to promote trust in them.

In The Guardian, Desmond Christy spoke of: 
... the real world, a place where facts are hard to come by, where science struggles to establish what the facts are, where the work of government scientists is suppressed, where grants are refused for work that might reach uncomfortable conclusions ... ${ }^{25}$

In "Getting Warmer, but Still a Long Way from our Goal: The Kyoto Climate Talks" (The Independent, 12 December 1997, long piece), Nicholas Schoon also exposed the agents in the wings of science and policy-making. About Sir John Houghton, the British scientist who led the IPCC, Charles Arthur observed that he "ha[d] fought to keep the IPCC politically neutral and scientifically rigorous" ("Global Warming now 'Unstoppable' Scientists Warn," The Independent, 23 January 2001).

In contrast, in The Times references to social and political contexts, or personal and institutional affiliations generally supported negative criticisms of science claims regarding climate change and its anthropogenic origin. In a long opinion article in The Sunday Times headlined "Calm Down, It Isn't the End of the World" (unattributed, 30 November 1997), non-governmental organizations and most scientists (including those of the IPCC) were presented as "visionary hobbits" who saw in global warming the doom of our age and "avoid[ed] economic 'progress' like the plague." The Times opposed "sense vs con-sense, rationality vs doggerel, moderates with both feet planted firmly on the earth against those with their heads in the clouds."

At around the time of the release of the third IPCC report, Barry Wigmore wrote that "doomsday weather scenarios [were] wrong" according to Dr. John Christy, "one of the world's foremost climatology experts" ("The Future Outlook is Fine," 20 February 2001). Note how a "dissident" view on climate change was socially legitimized:

Christy, 49, a father-of-two, often finds himself out of step with his peers. The weather tests he runs-with Nasa satellites and atmospheric balloons-are unlike most others and, he says, more accurate. ... He refuses funding from industry groups and works only with Nasa and other non-political scientific groups ...

Regarding the research instruments most widely used in climate sciences, "[h]e points out that no computer model accurately portrays even our current weather." The journalist inferred the following: "If climatologists can't get the present right, how can we trust them with the future?"

In the same line, Paul Hoggart ("Yesterday's Viewing," 23 February 2001) made the following comment about a BBC2 Horizon program on the state of the Earth 600 million years ago: "Snowball Earth was the heartwarming story of how a humble theory from a poor background ... fought its way from the academic gutter to the international big time." Distrust of science was fed with references to how "Friendly Scientist" A, B and so on put forth different claims "until our plucky little theory emerge[d] triumphant."

In this period, there was also a heightened reflexivity - an inclination to discuss the reporter's own values and views as well as the media's role in the social construction of scientific and political claims. ${ }^{26}$ All this means that there was a certain de-sacralization of science and scientific institutions in the media (cf. Nelkin, 1987, 1991).

In 1997, The Guardian and The Independent continued to alert the public to the risks associated with the climate change "supertanker" whose "irresistible force" had been "heading for collision with two twin, immovable objects-ordinary, everyday politics and economics." ${ }^{27}$

Nevertheless, William Hartston, a new contributor to The Independent and freelance science writer, wrote a series of features where he attempted to denounce unknowns and contradictions, cast doubts on scientific arguments and disqualify forecasts of negative impacts. The headlines were: "Current Ideas in Climate Research," 19 November 1997; "Taking a 
Cool Look at the Threat of Global Warming," 28 November 1997; "Warming or Cooling?," 1 December 1997; "The Politics of Climate," 4 December 1997; "Weather: The Very Model of a Global Argument," 9 December 1997; "Predictions of Doom and Disaster," 17 December 1997. By building a dismissive reading of climate change claims, Hartston sustained a field of inaction. Implicit in his discursive recreations of the problem is a legitimization of the practices that (others claim) originate it. The regular space awarded to Hartston in The Independent is strong evidence of an ideological division in this newspaper. An economically liberal ideology often coexisted with social responsibility in this paper.

Despite the matters discussed above, The Times was less engaged in contesting scientific claims on climate change in 1997 and 2001 than in previous years, pressed as it was by the increasing weight of scientific consensus. Still it dedicated only one article to the IPCC report in the months of January and February $2001,{ }^{28}$ clearly behind the four articles carried by The Independent ${ }^{29}$ and the three published by The Guardian $^{30}$ (which placed two on the front page).

\section{Conclusions}

Through the examination of news articles on climate change, this article has illustrated that there is a crucial cross-insemination between the normative and the descriptive, or the axiological and epistemological in the media's discursive reconstruction of science. Various dimensions of science representation have been shown to be interlinked with ideology in all the journalistic genres, from news reports to opinion articles. Firstly, ideology has implications for the interpretation of "facts." The reliability attributed by the media to scientific "truth" claims, the preferred definitions of "facts," and the quantity of media space dedicated to a given scientific claim simultaneously derive from and sustain a certain ideology. Secondly, the recognized agents of definition of scientific knowledge vary as a function of ideological standings. The selection of "experts" and "counter-experts" that are given voice depends on and reproduces certain worldviews. Thirdly, the goals associated with knowledge also have an ideological basis. The direct or indirect implications for individual or governmental action that are drawn from scientific claims result from views of the status quo and contribute to consolidating or challenging it.

\section{Synchronic comparison and diachronic analysis}

The chronological journey of this article has evidenced both continuities and transformations in the representation of scientific knowledge on climate change. It has also shown striking differences between newspapers. While the press acted jointly as spokespeople for the science establishment in the first few years examined in this article and enhanced its social authority and power, a radically different image started to emerge at the end of the 1980s, when climate change was politicized. Skepticism and contestation of mainstream scientific claims appeared in The Times and, to a lesser extent, in The Independent. In contrast with its earlier strategy of certainty-making, The Times cast doubts on the greenhouse effect and on human causation of the problem. Discrediting the agents of unwanted knowledge was part of that discursive route. When knowledge claims appeared to constitute a threat to ideological principles and arrangements in the political, social and economic realms, The Times did not hesitate to harm the reputation of an institution like the IPCC. In "critical discourse moments" like the release of IPCC reports, The Times picked individuals at the margins of respected science and magnified their opinions in order to sustain a certain view of 
the world and a certain social order. This was particularly evident in The Sunday Times, whose circulation is twice as large as The Times'.

In contrast, The Guardian and most authors in The Independent conveyed an image of scientific knowledge that emphasized the risks associated to climate change. Promoting confidence in science by emphasizing consensus and enhancing the reliability of knowledge, The Guardian and The Independent demanded a stronger political intervention on the problem. By re-configuring the state of scientific knowledge in ways that justify and promote preferred courses of social, economic and political action, newspapers discursively construct fields of action and fields of inaction.

For the last few years examined, this article has pointed out a tendency to openly discuss and denounce the material, political and ideological commitments of social actors. This is an important new dimension in the media construction of scientific knowledge.

As social studies of science have shown, science is always contextual and contingent. It is bound by political, institutional and personal factors and relies on a set of assumptions that are often questionable (e.g. Latour, 1987; Shackley and Wynne, 1995; Demeritt and Rothman, 1999). Yet, researchers have claimed that the media depict scientific work as an "arcane activity outside of, indeed, above the sphere of normal human understanding, and therefore beyond serious criticism" and scientists as "problem solvers, authorities, the ultimate source of truth" (Nelkin, 1991: xiii). The case reported in this article challenges these claims. Science was subjected to strong contestation in some media. It was depicted as plural and open-ended. Moreover, the contingent conditions of the production of science were often exposed. That served to construct science either as an authoritative and trustable source of knowledge or as a dismissable endeavor. The key factors to explain these variations in media discourses are ideological.

Modes of interpretation and discursive reconstitution of scientific uncertainty are one of the most telling indicators of ideological standpoints. Research has shown that the media have mainly conveyed an image of certainty of scientific knowledge on climate change in Germany (Weingart et al., 2000) and emphasized uncertainty in the US (e.g. McComas and Shanahan, 1999; Zehr, 2000; McCright and Dunlap, 2000, 2003; Boykoff and Boykoff, 2004; Antilla, 2005). In Britain, readings of uncertainty varied widely between newspapers. In The Times, and at points in The Independent, a focus on uncertainty aimed to de-legitimate scientific claims that climate change was taking place, to amplify an image of disagreement in the scientific community, and to de-authorize the agents and institutions that call for citizen and political mobilization to address climate change. The illations drawn from uncertainty about the goals to be pursued are equally variable. While some outlets discuss the issues involved in scientific uncertainty to reinforce the claim of the need for action, others use the same uncertainty as grounds for inaction on climate change. Like uncertainty, ignorance claims (Stocking and Holstein, 1993) were also appropriated by the media in widely different forms. As we have seen, in conditions of incomplete or uncertain knowledge, The Guardian and some authors in The Independent strongly promoted the precautionary principle, defending mitigating action in relation to climate change. The Times and others in The Independent advocated business-as-usual using the lack of definitive proof as justification for the continuation of policies and practices.

Studies of the American media (e.g. Zehr, 2000; Boykoff and Boykoff, 2004) have shown that scientific consensus on climate change has been subjected to a great deal of contestation in the "prestige" papers, such as the New York Times, the Washington Post, the Los Angeles Times and the Wall Street Journal. However, such studies have not systematically examined the differences between news organs, something that this article demonstrates to be crucial. Such differences are very significant as they correspond to particular worldviews 
that different audiences are continuously fed and go on subscribing to. The representation of scientific knowledge has important implications for evaluating political programs and assessing the responsibility of both governments and the public in addressing climate change. As shown here, each newspaper may have helped sustain or dispute given policy choices.

\section{News organizations and ideological cultures}

Some might be tempted to explain variations in the representation of science as a matter of partisan bias. This study indicates that, although that may be a factor, it is far from unique. In The Guardian and The Independent, scientific reporting may have been a weapon of political attack with regard to Tory governments. Yet, we must note that their emphasis on the risks associated to climate change did not contradict Margaret Thatcher's dramatization of the issue: they wanted the government to go further. Instead, it was the Conservative Times that built the scientific grounds against political mobilization.

Forms of filtering and reinterpreting information about climate change are rooted in, and reproduce, profoundly divergent value systems. As also shown by analysis of discourse on the politics of climate change (Carvalho, 2005), an ideological culture of neo-liberal capitalism is hegemonic in The Times. The Times obviously has a Conservative stance on politics. But this is a shade of Conservatism that is not concerned with the long term or with risk to the preservation of conditions for future generations. In the center of the ideological constellation of this newspaper is aversion to political control. The free market, individualism and a Promethean view of man's relations with the environment also feature highly. ${ }^{31}$ Maintaining an image of scientific non-closure helped The Times contest (inter)governmental measures to combat greenhouse emissions and legitimate the existing economic and social order.

A social democratic ideology is central in The Guardian, with values of equity and solidarity often being voiced. The Guardian is also prone to an ethics of the global. By highlighting scientific claims on the risks of climate change to distant physical and human environments, The Guardian stimulated a sense of global connectedness and global responsibility. In spite of leaning often to the views of The Times, the dominant culture in The Independent is close to The Guardian's.

Human agency with regard to nature is viewed very differently across the three newspapers. The Times typically attempts to exempt humans from interference with nature. Hartston and others in The Independent do the same. The Guardian and most in The Independent view human exploitation of nature as potentially dangerous. Still, their standings fit into "shallow ecology." The issue of the intrinsic value of nature is excluded from all the papers and anthropocentrism is hegemonic.

The Guardian and, although to a smaller degree The Independent, favor a stronger regulation of the market but neither shakes the main capitalist structures. As argued by Edwards and Cromwell (2005), the values often found in the texts of the "liberal" Guardian and Independent clash with their promotion of indiscriminate consumerism through advertising of cheap flights, gas-guzzling cars and bargain holidays abroad. These papers also do not risk antagonizing big business with an exposure of the real impact of their practices on climate change.

The concept of ideological culture proposed in this article intends to refer to communities of ideas, values and preferences inside media organizations and in their particular audiences. The term culture points to the socially constructed nature of ideologies. Values and norms are, to some extent, always shared. This does not mean that ideologies are internalized 
by individuals in a fixed and uniform way. In the term culture there is room for some pluralism and diversity, as illustrated by differences between Nick Nuttall and Nigel Hawkes in The Times. Values and worldviews seem to matter at the individual level too. They may explain the coherent discursive standpoints of Nicholas Schoon (The Independent) and Paul Brown (The Guardian), ${ }^{32}$ for example. These journalists recurrently presented the current economic and political status quo as a threat for environmental security in the future and promoted its transformation. Contrastingly, contributors such as Wilfred Beckerman (The Independent and The Times) and Irwin Stelzer (The Times) constructed the present system as a good one and attempted to reinforce it.

The concept of ideological culture is not equivalent to the notion of professional culture, which entails ideas about journalistic practice and news values. News values of conflict and controversy, together with the wish for "balance," could partly explain the praise of dissent with regard to climate change. Still, this does not justify the frequency of editorials dismissing scientific claims regarding climate change in The Times, for example.

Kellner (1995: 56) argues that we should "read media culture politically," aware that media texts embody certain political and ideological positions and have political effects. In this article, I propose a politicized reading of science reports in the press. Given that the media read scientific papers politically, so should we read the newspapers. In doing so, audiences could engage in a more active interpretation of representations of knowledge in the media and in a critical understanding of their implications. Academics have an important responsibility in fomenting media literacy on science issues and in advancing the tools for a critical deconstruction of science communication.

\section{Acknowledgements}

The author would like to thank Jacquie Burgess for her contribution to this research and David Demeritt for comments on an earlier version of the paper. Several institutions provided financial support: Universidade do Minho, Fundação para a Ciência e Tecnologia, and Centro de Ciências Históricas e Sociais (Universidade do Minho).

\section{Notes}

An earlier version of this paper was presented at a conference entitled "Does Discourse Matter? Discourse, Power and Institutions in the Sustainability Transition,” Hamburg, 11-13 July 2003.

1 The phrase "quality press" is equivalent to "prestige press" (cf., for instance, Sparks, 1987; d'Haenens, 2005).

2 See Bell (1994) on climate change reports in the media.

3 The Independent was launched on 7 October 1986.

4 References to the pages where articles appeared and to their size will be here reserved to articles that stand out most, i.e. those that were published on the front page, on page 3 or were longer than 1,000 words (although a somewhat artificial "boundary," this limit helps us draw attention to those pieces that were larger than average and that will be qualified as "long").

5 Robin Oakley, “Nuclear Power is 'Greener' Says Thatcher,” 26 October 1988.

6 E.g. Tim Radford, "The Edge of Darkness," 2 November 1988 (very long article of 1,530 words).

7 E.g. Nicholas Schoon, "Experts See Better Ways to Counter Global Warming," 7 November 1988.

8 Although all the IPCC's Assessment Reports also include volumes on impacts of climate change and mitigation options, only the one on "science" will be referred to.

9 Paul Brown and Nigel Williams, "Climate Pledge 'Too Little Too Late,'” 26 May 1990, page 1; Andrew Warren, "Climate: Following Mrs Thatcher's recognition of the threat of global warming, Environment Guardian asked for practical solutions that she might encourage," 1 June 1990.

10 Contrast this stance with the survivalist discourse of Nigel Fountain in "Echoes of Disaster for this Island Earth," The Guardian, 30 May 1990. 
11 The UNFCCC had been signed at the Rio conference in 1992 and set the basis for internationally concerted policies to address the greenhouse effect.

12 E.g. Irwin Stelzer, "Fossil Fuel: Heat and Green Smoke," The Sunday Times, 9 April 1989; Mark Hosenball, "Is it a Warmed-up World or Just a Load of Hot Air?," The Sunday Times, 22 April 1990 (both are long articles).

13 Paul Brown, "Our Man in the Greenhouse," 29 March 1995; Polly Ghazi, "Heat is on to Stop the Slow Thaw," The Observer, 26 March 1995 (long article).

14 "A Climate of Confusion," 27 March 1995; "The Clouds Part on a Mystery," 10 July 1995. Burroughs authored several other articles for The Times, in the same vein, from 1987 to 1996.

15 "Keeping Cool," 17 April 1995; "Headache for the Whales?," 19 June 1995; "New Evidence Proves that Antarctic Ice is Melting," 10 August 1995; "Astronomers Are Spot On," 28 August 1995; and "Warm Water Storm Signal," 20 November 1995.

16 “A Good Dose of Iron Could Halt Global Warming," 29 June 1995.

17 "Breathe Easy," 28 August 1995.

18 E.g. "Arctic Trees Show Signs of Life as Temperatures Rise," 25 March 1995; "Where Are all our Salmon?," 5 June 1995; "Global Warming Tempts Native Butterflies North," 24 October 1995.

19 "Tree Rings Hold Clue to the Hottest News this Century," 13 July 1995.

20 Gelbspan (1997) describes the involvement of Patrick Michaels with the "public relations apparatus" of the coal industry and how he has been heavily funded by fossil fuel interests.

21 Paul Brown, "Climate: Emissions Turn up the Heat," 5 December 1995 (long article).

22 Paul Brown, 5 December 1995.

23 Paul Brown, "Climate: A Race against Time," 5 December 1995.

24 Desmond Christy, "Last Night's TV: You Don't Want to do That," The Guardian, 12 December 1997; Robin Mckie, "Damming Major Rivers is Pulling the Gulf Stream Nearer," The Guardian, 30 November 1997; Nicholas Schoon, "Getting Warmer, but Still a Long Way from our Goal: The Kyoto Climate Talks," The Independent, 12 December 1997 (long “comment" piece).

25 Desmond Christy, 12 December 1997. See also Robin Mckie, 30 November 1997.

26 Nicholas Schoon, 12 December 1997; Geoffrey Lean, "It May be our Last Chance: This Week 166 Countries Can Halt Global Warming," Independent on Sunday, 30 November 1997 (long “comment” piece); Desmond Christy, 12 December 1997; Nicholas Schoon, "Greedy Americans and Nice, Wet Europeans-the Politics of Weather," The Independent, 29 November 1997 (long "comment" piece).

27 Nicholas Schoon, "Trying to Slow the Global Warming Supertanker," The Independent, 24 November 1997. In The Guardian, see, for example, Tim Radford, "Record Global Temperatures Bring Scientists Cold Comfort"; Tim Radford, "Summer in SpitsBritain"; and "Meltdown: How Global Warming Could Make Britain Much Colder" (unattributed), all on page 3, 28 November 1997.

28 Nigel Hawkes, "Global Warming "Will be Twice as Bad,", 22 January 2001, page 3.

29 Geoffrey Lean, "Warming_it's Twice as Bad as we Thought," 21 January 2001; Michael McCarthy, "World Will be 6C Warmer by 2100, Scientists Forecast," 22 January 2001; Charles Arthur, "Global Warming now 'Unstoppable' Scientists Warn," 23 January 2001; Michael McCarthy, "UN Delivers Apocalyptic Warning on Climate Global Warming," 20 February 2001.

30 Tim Radford and Paul Brown, "Warming Could be Worst in 10,000 Years," 23 January 2001, page 1; Paul Brown, "Global Warming: A World of Extremes as the Planet Hots Up," 23 January 2001, pages 1, 17; Paul Brown and Peter Capella, "Grim Forecast, Warns Climate Report," 20 February 2001.

31 See Jameson (1994) on "market ideology" and the totalizing nature of the concept of market.

32 Paul Brown's personal views on climate change are available in his book on the subject. There he argues that "[p]otentially unpopular political decisions have to be taken to mitigate [the] effects [of climate change]" (1996: 199).

\section{References}

Allan, S. (1999) News Culture. Buckingham: Open University Press.

Allan, S., Adam, B. and Carter, C., eds (2000) Environmental Risks and the Media. London and New York: Routledge.

Anderson, A. (1997) Media, Culture and the Environment. London: University College Press.

Antilla, L. (2005) "Climate of Scepticism: US Newspaper Coverage of the Science of Climate Change," Global Environmental Change 15: 338-52.

Beck, U. (1992) Risk Society: Towards a New Modernity. London: SAGE.

Bell, A. (1994) "Media (Mis)Communication on the Science of Climate Change," Public Understanding of Science 3: 259-75. 
Bennett, L. (1988) News: The Politics of Illusion. New York and London: Longman.

Boykoff, M. and Boykoff, J. (2004) "Balance as Bias: Global Warming and the US Prestige Press," Global Environmental Change 14: 125-36.

Brown, P. (1996) Global Warming: Can Civilization Survive? London: Blandford.

Bucchi, M. (1998) Science and the Media: Alternative Routes in Scientific Communication. London: Routledge.

Burgess, J., Harrison, C. and Maiteny, P. (1991) "Contested Meanings: The Consumption of News about Nature Conservation," Media, Culture and Society 13(4): 499-519.

Carvalho, A. (2002) "Climate in the News: The British Press and the Discursive Construction of the Greenhouse Effect," Ph.D. thesis, University College London.

Carvalho, A. (2005) "Representing the Politics of the Greenhouse Effect: Discursive Strategies in the British Media," Critical Discourse Studies 2(1): 1-29.

Corbett, J. and Durfee, J. (2004) "Testing Public (Un)Certainty of Science: Media Representations of Global Warming," Science Communication 26(2): 129-51.

Demeritt, D. and Rothman, D. (1999) "Figuring the Costs of Climate Change: An Assessment and Critique," Environment and Planning A 31: 389-408.

d'Haenens, L. (2005) "Euro-Vision. The Portrayal of Europe in the Quality Press," Gazette 67(5): 419-40.

Dryzek, J. (1997) The Politics of the Earth: Environmental Discourses. Oxford: Oxford University Press.

Eagleton, T. (1991) Ideology: An Introduction. London: Verso.

Edmond, G. and Mercer, D. (1999) “Creating (Public) Science in the Noah's Ark Case," Public Understanding of Science 8(4): 317-43.

Edwards, D. and Cromwell, D. (2005) Guardians of Power: The Myth of the Liberal Media. London: Pluto.

Einsiedel, E. and Coughlan, E. (1993) "The Canadian Press and the Environment: Reconstructing a Social Reality," in A. Hansen (ed.) The Mass Media and Environmental Issues, pp. 134-49. Leicester: Leicester University Press.

Entman, R. (1993) "Framing: Toward Clarification of a Fractured Paradigm," Journal of Communication 43(4): 6-27.

Fairclough, N. (1995) Media Discourse. London: Edward Arnold.

Friedman, S., Dunwoody, S. and Rogers, C. (1986) Scientists and Journalists: Reporting Science as News. New York: Free Press.

Gamson, W. (1999) "Beyond the Science-Versus-Advocacy Distinction," Contemporary Sociology 28(1): $23-6$.

Gamson, W. and Modigliani, A. (1989) "Media Discourse and Public Opinion on Nuclear Power: A Constructionist Approach," American Journal of Sociology 95(1): 1-37.

Gans, H. (1979) Deciding What's News: A Study of CBS Evening News, NBC Nightly News, Newsweek and Time. New York: Pantheon.

Gelbspan, R. (1997) The Heat is On: The High Stakes Battle over Earth's Threatened Climate. Reading, MA: Addison-Wesley.

Gregory, J. and Miller, S. (1998) Science in Public: Communication, Culture and Credibility. New York and London: Plenum Trade.

Hajer, M. (1995) The Politics of Environmental Discourse: Ecological Modernization and the Policy Process. Oxford: Clarendon Press.

Hall, S., Critcher, C., Jefferson, T., Clarke, J. and Roberts, B. (1978) Policing the Crisis: Mugging, the State, and Law and Order. London: Macmillan.

Hansen, A. (1994) "Journalistic Practices and Science Reporting in the British Press," Public Understanding of Science 3: 111-34.

Intergovernmental Panel on Climate Change (IPCC) (1990) Scientific Assessment of Climate Change: Report of Working Group I. Cambridge: Cambridge University Press.

Intergovernmental Panel on Climate Change (IPCC) (1996) Climate Change 1995: The Science of Climate Change. Cambridge: Cambridge University Press.

Intergovernmental Panel on Climate Change (IPCC) (2001) Climate Change 2001: The Scientific Basis. Cambridge: Cambridge University Press.

Irwin, A. (1995) Citizen Science: A Study of People, Expertise and Sustainable Development. London: Routledge.

Jameson, F. (1994) "Postmodernism and the Market," in S. Zizek (ed.) Mapping Ideology, pp. 278-95. London: Verso.

Kellner, D. (1995) Media Culture: Cultural Studies, Identity and Politics between the Modern and the Postmodern. London: Routledge.

Krosnick, J., Holbrook, A. and Visser, P. (2000) "The Impact of the Fall 1997 Debate about Global Warming on American Public Opinion," Public Understanding of Science 9(3): 239-60.

Lahsen, M. (2005) "Technocracy, Democracy, and U.S. Climate Politics: The Need for Demarcations," Science, Technology, \& Human Values 30(1): 137-69. 
Latour, B. (1987) Science in Action: How to Follow Scientists and Engineers through Society. Cambridge, MA: Harvard University Press.

Lull, J. (1995) Media, Communication, Culture: A Global Approach. Cambridge: Polity.

McComas, K. and Shanahan, J. (1999) "Telling Stories about Global Climate Change: Measuring the Impact of Narratives on Issue Cycles," Communication Research 26(1): 30-57.

McCright, A. and Dunlap, R. (2000) "Challenging Global Warming as a Social Problem: An Analysis of the Conservative Movement's Counter-claims," Social Problems 47(4): 499-522.

McCright, A. and Dunlap, R. (2003) "Defeating Kyoto: The Conservative Movement's Impact on U.S. Climate Change Policy," Social Problems 50(3): 348-73.

Nelkin, D. (1987) Selling Science: How the Press Covers Science and Technology. New York: W.H. Freeman.

Nelkin, D. (1991) "Why is Science Writing so Uncritical of Science?," in L. Wilkins and P. Patterson (eds) Risky Business: Communicating Issues of Science, Risk and Public Policy, pp. ix-xiii. New York: Greenwood Press.

Schwarz, M. and Thompson, M. (1990) Divided We Stand: Redefining Politics, Technology and Social Choice. Hemel Hempstead: Harvester Wheatsheaf.

Seliger, M. (1977) The Marxist Conception of Ideology: A Critical Essay. Cambridge: Cambridge University Press.

Shackley, S. and Wynne, B. (1995) "Global Climate Change: The Mutual Construction of an Emergent SciencePolicy Domain," Science and Public Policy 22: 218-30.

Sparks, C. (1987) “The Readership of the British Quality Press,” Media, Culture and Society 9: 427-55.

Stocking, S. and Holstein, L. (1993) "Constructing and Reconstructing Scientific Ignorance: Ignorance Claims in Science and Journalism," Knowledge-Creation, Diffusion, Utilization 15(2): 186-210.

Szerszynski, B. and Toogood, M. (2000) "Global Citizenship, the Environment and the Media," in S. Allan, B. Adam and C. Carter (eds) Environmental Risks and the Media, pp. 218-28. London and New York: Routledge.

Trumbo, C. (1996) "Constructing Climate Change: Claims and Frames in US News Coverage of an Environmental Issue," Public Understanding of Science 5: 269-73.

van Dijk, T. (1988) News as Discourse. Hillsdale, NJ: Laurence Erlbaum.

van Dijk, T. (1991) Racism and the Press. London: Routledge.

van Leeuwen, T. and Wodak, R. (1999) "Legitimizing Immigration Control: A Discourse-Historical Analysis," Discourse Studies 1(1): 83-118.

Weingart, P., Engels, A. and Pansegrau, P. (2000) "Risks of Communication: Discourses on Climate Change in Science, Politics, and the Mass Media," Public Understanding of Science 9: 261-83.

Wilkins, L. (1993) "Between Facts and Values: Print Media Coverage of the Greenhouse Effect, 1987-1990," Public Understanding of Science 2(1): 71-84.

Wilson, K. (1995) "Mass Media as Sources of Global Warming Knowledge," Mass Communication Review 22(1-2): 75-89.

Wodak, R., de Cillia, R., Reisigl, M. and Liebhart, K., eds (1999) The Discursive Construction of National Identity. Edinburgh: Edinburgh University Press.

Zehr, S. (2000) "Public Representations of Scientific Uncertainty about Global Climate Change," Public Understanding of Science 9: 85-103.

\section{Author}

Anabela Carvalho is Assistant Professor at the Department of Communication Sciences of the University of Minho, Portugal, and currently Director of Undergraduate Studies in Communications. She received her Ph.D. from University College London (Department of Geography) and has been conducting research on media representations of social and political issues and on various forms of environmental communication. She has published on topics such as discourses on climate change, the present challenges for science communication and depictions of the Iraq war in the media in Comunicação e Sociedade, Critical Discourse Studies, Risk Analysis and other journals and edited books. Correspondence: Departamento de Ciências da Comunicação-ICS, Universidade do Minho, Campus de Gualtar, 4710-057 Braga, Portugal; e-mail: carvalho@ics.uminho.pt 